\title{
Effect of Yogic and Recreational Activities for Improving Self- injurious and Aggression Behavior of Autistic Children
}

\author{
Neelam Sharma \& Nidhi Sharma \\ Lovely Professional University, Phagwara, Punjab
}

\begin{abstract}
Autism is a multifaceted neuro-behavioral disorder and includes impairments in language, social interaction and communication skills. The purpose of the present study was to examine the effect of yogic and recreational activities for improving self injurious and aggressive behaviour of autistic children. The study was conducted on twenty (20) autistic children of age group of 8-14 years. Further, respondents were divided into three equal groups namely i.e yogic group, recreational group and control group. Two years' selected training program, based on the interest and connotation of respondents, were given to the subjects. Before imparting the session of yoga and recreation activities, pre-test data were obtained through Autistic Distress behavior standardized scale. Pre and post-test data were collected by imparting selected training programme to the subjects. No experimental treatment was given to control group. The results of present investigation affirm positive effects of recreational and yogic activities.
\end{abstract}

Keywords: Autism,Yoga, Recreation, Self injury, Aggression, Behaviour

\section{Introduction}

Autism is an inborn disease of neural development in which the first behavioral symptoms appear early in life. Clinically autism is described as intricate social interaction, intricate communication, limited interest and repetitive behaviours. Both self-injury and aggression behaviours are a recurrent and serious problem for autistic children. Almost 50\% of autistic children show signs of Self injury and aggression in their behaviour. This behaviour creates barrier for the children to participate in integrated activities in the community with typically developing peers and causes major stress for the family. Leisure and recreation means participation in any activity for entertainment and relaxation. Recreation is independent, cooperative, or competitive sports, games, hobbies, or toy play. Participation in recreational activities has extensive benefits for every child. As compare to normal children, autistic children have less participation in recreation and leisure activities. Parents, teachers and therapist always search the interest of autistic children in recreational activities. An individual's normal as well autistic favorite recreation activities may vary with age and interests. Recreation is an important phase of life for everyone and plays an important role in the lives of everyone. Every one noticed that autistic individuals have higher levels of isolation and social dissatisfaction than normal children, and recreational activities make a path to contact people with each other gives momentous opportunities to perform and expand social skills and form a relationship. Yoga, according to Galantino, Galbavy, and Quinn (2008), can increase concentration ability, focus, and improve memory. Yoga means simultaneously participation of brain and body. The application of yoga practice for autistic children is to create 
stability of mind to regulate body withyoga practices. Yoga maintains balance between mind and body. This interconnectedness works to reduce aggression and self injury.

\section{Objectives:}

1. To scrutinize the effect of yogic activities on self injurious behavior of autistic children.

2. To analyze the effect yogic on aggression behavior of autistic children

3. To examine the effect of recreational activities on self injurious behavior of autistic children.

4. To analyse the effect of recreational activities on aggression behavior of autistic children.

\section{Hypotheses}

1. Yogic activities significantly effect on self injurious behavior of autistic children.

2. Yogic activities significantly effect on aggression behavior of autistic children

3. Recreational activities significantly effect on self injurious behavior of autistic children.

4. Recreational activities have significant effect on aggression behavior of autistic children.

\section{Methodology}

\section{Sample:}

Twenty (20) autistic children between the age group of 8 to 14 years from Mini Bright Future Mentally Challenged School Gosianpur, Punjab, India including their parents and teachers were selected for the present study. Prior Permission was taken from school authorities to conduct the experiment. Teachers and parents signed an informed concent form for their true, honest and active participation in the study. The involvement in this was conducted on a voluntary basis.

\section{Selection of variables}

Yogic and recreational activities created the manipulation on self-injurious and aggressive behaviour so these were considered as independent variable and self injurious and aggression were considered as the dependent variable.

\section{Training Design}

After the suggestions given by the expert, recreational and yogic activities programme were prepared on the basis of the interest of the subjects. Training of selected recreational, yogic and both recreational-yogic activities was imparted to the subjects six days in a week for ninety (90) weeks. There were two session in a day i.e morning (7 to 9 am approx) and evening (5:30 to 7:30 approx). Yogic activities comprises Halasana, Trikonaassana, Padamasana, Naukaasana, Vajarasana, Shavasana, Titaliasana, Sarvagasana, Tadasana, Dhanurasana, Bhujangasana, Paschimottanasana,Vrikshasana, Suryanamskar, Bhramari Pranayama, Kapalbhati, Ujjai Pranayama, Auloma Viloma, Virbhdarasana, Meditation.

Recreational activities includes: Stand-up and sit-down, baby-walk , on-the-spot-jump, matching colours of balloons, nail-paint, crazy cards, matching flowers, matching pet toys, vegetables and fruits, soft ball throw, bowling, Arrange the circle, Rapid fire, and many physical exercises. 


\section{Tool for Data Collection}

Self-made scale was prepared by the investigatsors to find out the effect of recreational activities on aggression and self injurious behavior of autistic children. The scale was constructed and standardized in consultation with national and international professional and psychiatrists. Apart from this, the researcher went through review of related literature, various tests and books for observation. The suggestions of 40 experts were incorporated for the better validity of the scale.

\section{Statistical Design}

Analysis of covariance (ANCOVA) along with descriptive statistics was used as the statistical technique on SPSS at 0.05 levels of significance.

\section{Results and Analysis}

Table: - 1

Descriptive statistics in relation to Self Injurious behaviour of autistic children

\begin{tabular}{|c|c|c|c|c|c|c|c|c|c|c|c|c|}
\hline \multirow{3}{*}{$\begin{array}{c}\text { Self } \\
\text { Injurious }\end{array}$} & \multicolumn{4}{|c|}{ Mother } & \multicolumn{4}{|c|}{ Father } & \multicolumn{4}{|c|}{ Teacher } \\
\hline & \multicolumn{2}{|c|}{ Pre Test } & \multicolumn{2}{|c|}{ Post Test } & \multicolumn{2}{|c|}{ Pre Test } & \multicolumn{2}{|c|}{ Post Test } & \multicolumn{2}{|c|}{ Pre Test } & \multicolumn{2}{|c|}{ Post Test } \\
\hline & Mean & SD & Mean & SD & Mean & SD & Mean & SD & Mean & SD & Mean & SD \\
\hline Yoga & 53.60 & 0.54 & 32.40 & 0.89 & 53.40 & 0.54 & 31.20 & 0.44 & 53.86 & 0.49 & 31.80 & 0.62 \\
\hline Recreation & 53.60 & 0.54 & 35.20 & 1.30 & 53.60 & 0.54 & 34.60 & 1.51 & 53.83 & 0.66 & 35.50 & 1.34 \\
\hline $\begin{array}{c}\text { Yogic- } \\
\text { Recreational }\end{array}$ & 53.40 & 1.14 & 34.00 & 1.22 & 53.60 & 1.14 & 33.40 & 1.34 & 53.90 & 0.57 & 33.86 & 1.10 \\
\hline Control & 53.20 & 1.48 & 49.20 & 1.92 & 53.80 & 1.30 & 48.60 & 1.81 & 53.60 & $0.5^{2}$ & 49.16 & 2.07 \\
\hline
\end{tabular}

Table 1 shows the mean and standard deviation of Pre test and Post test of yoga, Recreation, Yogic-Recreational and Control groups in relation to self injurious behaviour of autistic children by mother, father and teacher.

Mean and standard deviation of Pre test of yoga group in relation to self injurious behaviour of autistic children by mother, father and teacher were 53.60 and 0.54, 53.40 and 0.54, 53.86 and 0.49 where as Mean and standard deviation Post test of yoga group in relation to self injurious behaviour of autistic children by mother, father and teacher were 32.40 and 0.89 , 31.20 and $0.44,31.80$ and 0.62

Mean and standard deviation of Pre test of Recreation group in relation to self injurious behaviour of autistic children by mother, father and teacher were 53.6o and 0.54, 53.6o and o.54, 53.83 and 0.66 where as Mean and standard deviation Post test of Recreation group in relation to self injurious behaviour of autistic children by mother, father and teacher were 35.20 and 1.30, 34.60 and $1.51,35.50$ and 1.34

Mean and standard deviation of Pre test of Yogic-Recreational group in relation to self injurious behaviour of autistic children by mother, father and teacher were 53.40 and 1.14, 53.60 and 1.14, 53.90 and 0.57 where as Mean and standard deviation Post test of both group in relation 
to self injurious behaviour of autistic children by mother, father and teacher were 34.00 and 1.22 , 33.40 and $1.34,33.86$ and 1.10

Mean and standard deviation of Pre test of control group in relation to self injurious behaviour of autistic children by mother, father and teacher were 53.20 and 1.48, 53.80 and 1.30, 53.6o and 0.52 where as Mean and standard deviation Post test of control group in relation to self injurious behaviour of autistic children by mother, father and teacher were 49.20 and 1.92, 48.60 and 1.81, 49.16 and 2.0.

Table: - 2

Analysis of covariance of comparison of post test means of Experimental group and Control group in relation to Self Injurious behaviour of autistic children

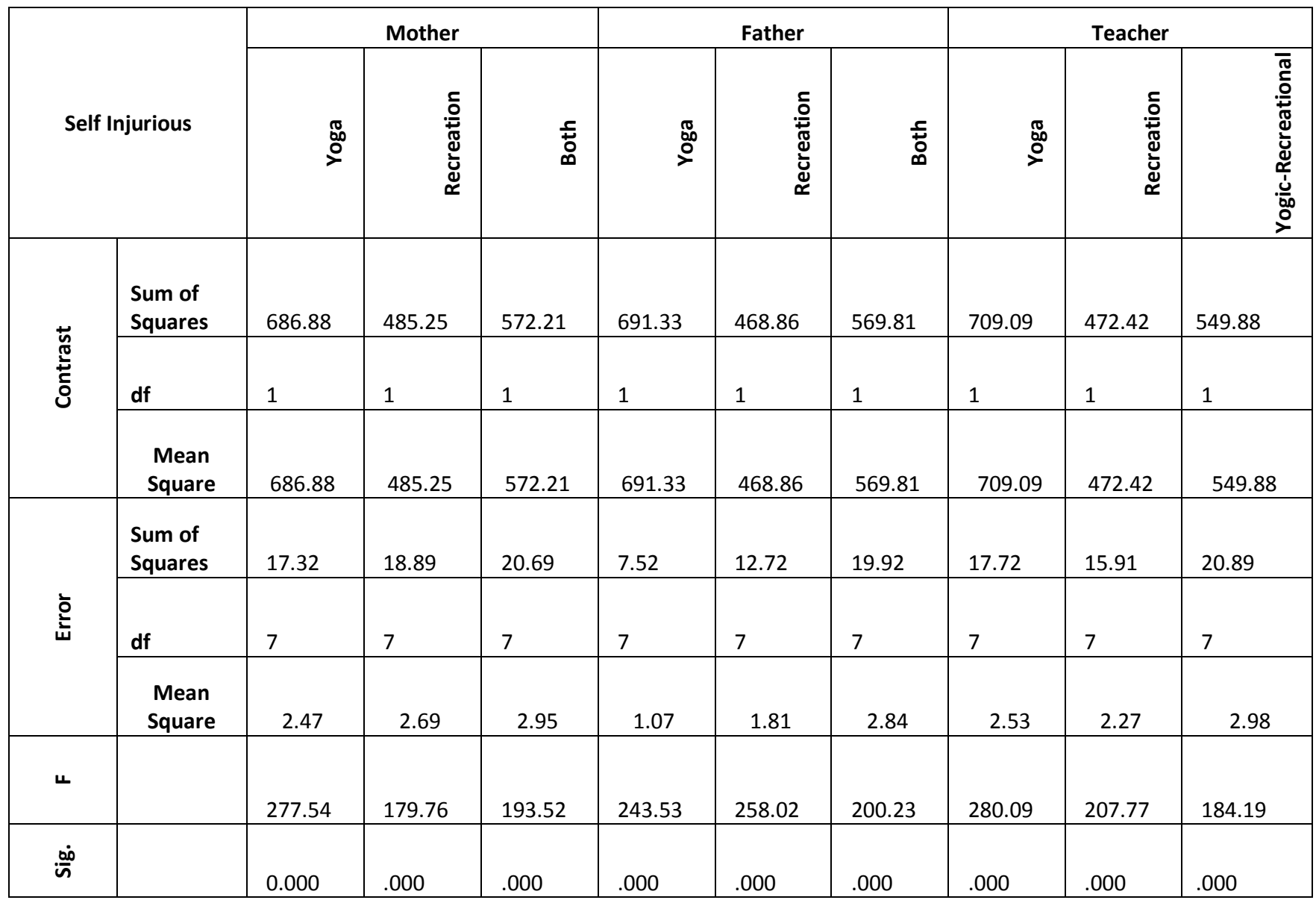

${ }^{*}$ Significant at 0.05 level $_{(1,7)} \mathrm{df}=5.59$

Table 2 shows the $\mathrm{f}$ ratio of yoga, Recreation, Yogic-Recreational and Control groups in relation to self injurious behaviour of autistic children by mother, father and teacher.

In Yoga the Sig value was found .ooo, which is less than 0.05 and the calculated $f$-value for mother 277.54 , father 243.53 and teacher 280.09 was found to be greater than tabulated value $=$ 5.59 at $1,7 \mathrm{df}$, therefore it shows significance difference between the group.

In Recreation the Sig value was found .ooo, which is less than 0.05 and the calculated $\mathrm{f}$ value for mother 193.52, father $\mathbf{2 5 8 . 0 2}$ and teacher 207.77 was found to be greater than tabulated value $=5.59$ at $1,7 \mathrm{df}$, therefore it shows significance difference between the group. 
In Yoga-Recreation the Sig value was found .0oo, which is less than 0.05 and the calculated f-value for mother 179.76, father 200.23 and teacher 184.19 was found to be greater than tabulated value $=5.59$ at $1,7 \mathrm{df}$, therefore it shows significance difference between the group.

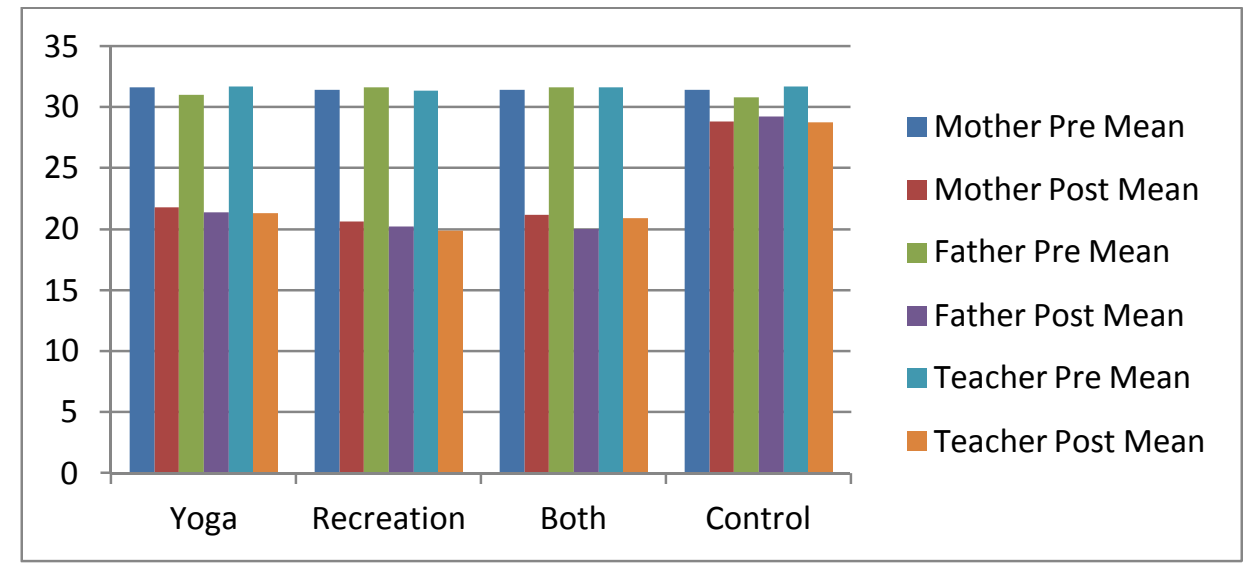

Table: -3

Descriptive statistics in relation to Aggression behaviour of autistic children

\begin{tabular}{|c|c|c|c|c|c|c|c|c|c|c|c|c|}
\hline \multirow[b]{3}{*}{ Aggression } & \multicolumn{4}{|c|}{ Mother } & \multicolumn{4}{|c|}{ Father } & \multicolumn{4}{|c|}{ Teacher } \\
\hline & \multicolumn{2}{|c|}{ Pre Test } & \multicolumn{2}{|c|}{ Post Test } & \multicolumn{2}{|c|}{ Pre Test } & \multicolumn{2}{|c|}{ Post Test } & \multicolumn{2}{|c|}{ Pre Test } & \multicolumn{2}{|c|}{ Post Test } \\
\hline & Mean & SD & Mean & SD & Mean & SD & Mean & SD & Mean & SD & Mean & SD \\
\hline Yoga & 31.60 & 0.54 & 21.80 & 1.48 & 31.00 & 1.22 & 21.40 & 1.67 & 31.70 & 0.24 & 21.33 & 0.52 \\
\hline Recreation & 31.40 & 0.54 & 20.60 & 0.89 & 31.60 & 0.54 & 20.20 & 0.44 & 31.33 & 0.16 & 19.86 & 0.43 \\
\hline $\begin{array}{l}\text { Yogic- } \\
\text { Recreational } \\
\end{array}$ & 31.40 & 0.54 & 21.20 & 1.30 & 31.60 & 0.89 & 20.00 & .70 & 31.60 & .25 & 20.86 & .33 \\
\hline Control & 31.40 & 0.54 & 28.80 & 1.30 & 30.80 & 0.83 & 29.20 & 1.30 & 31.66 & .20 & 28.76 & .93 \\
\hline
\end{tabular}

Table 3 shows the mean and standard deviation of Pre test and Post test of yoga, Recreation, Yogic-Recreational and Control groups in relation to aggression behaviour of autistic children by mother, father and teacher.

Mean and standard deviation of Pre test of yoga group in relation to aggression behaviour of autistic children by mother, father and teacher were 31.60 and $0.54,31.00$ and 1.22, 31.70 and 0.24 whereas Mean and standard deviation Post test of yoga group in relation to self injurious behaviour of autistic children by mother, father and teacher were 21.80 and 1.48, 21.40 and 1.67, 21.33 and 0.52 .

Mean and standard deviation of Pre-test of Recreation group in relation to aggression behaviour of autistic children by mother, father and teacher were 31.40 and $0.54,53.60$ and 0.54 , 31.33 and 0.54 where as Mean and standard deviation Post test of Recreation group in relation to self injurious behaviour of autistic children by mother, father and teacher were 20.60 and 0.89 , 20.20 and $0.89,19.86$ and 0.43

Mean and standard deviation of Pre-test of Yogic-Recreational group in relation to aggression behaviour of autistic children by mother, father and teacher were 31.40 and o .54, 31.60 and $0.89,31.60$ and 0.57 where as Mean and standard deviation Post test of both group in relation to self injurious behaviour of autistic children by mother, father and teacher were 21.20 and 1.30, 20.00 and $0.70,20.86$ and 0.33 . 
Mean and standard deviation of Pre-test of control group in relation to aggression behaviour of autistic children by mother, father and teacher were 31.40 and 0.54 , 30.80 and o.83, 31.66 and 0.20 where as Mean and standard deviation Post test of control group in relation to self injurious behaviour of autistic children by mother, father and teacher were $28.80 a n d$ 1.30, 29.20 and 1.30, 28.76 and 0.93 .

Table: -4

Analysis of covariance of comparison of post test means of Experimental group and Control group in relation to Aggression behaviour of autistic children

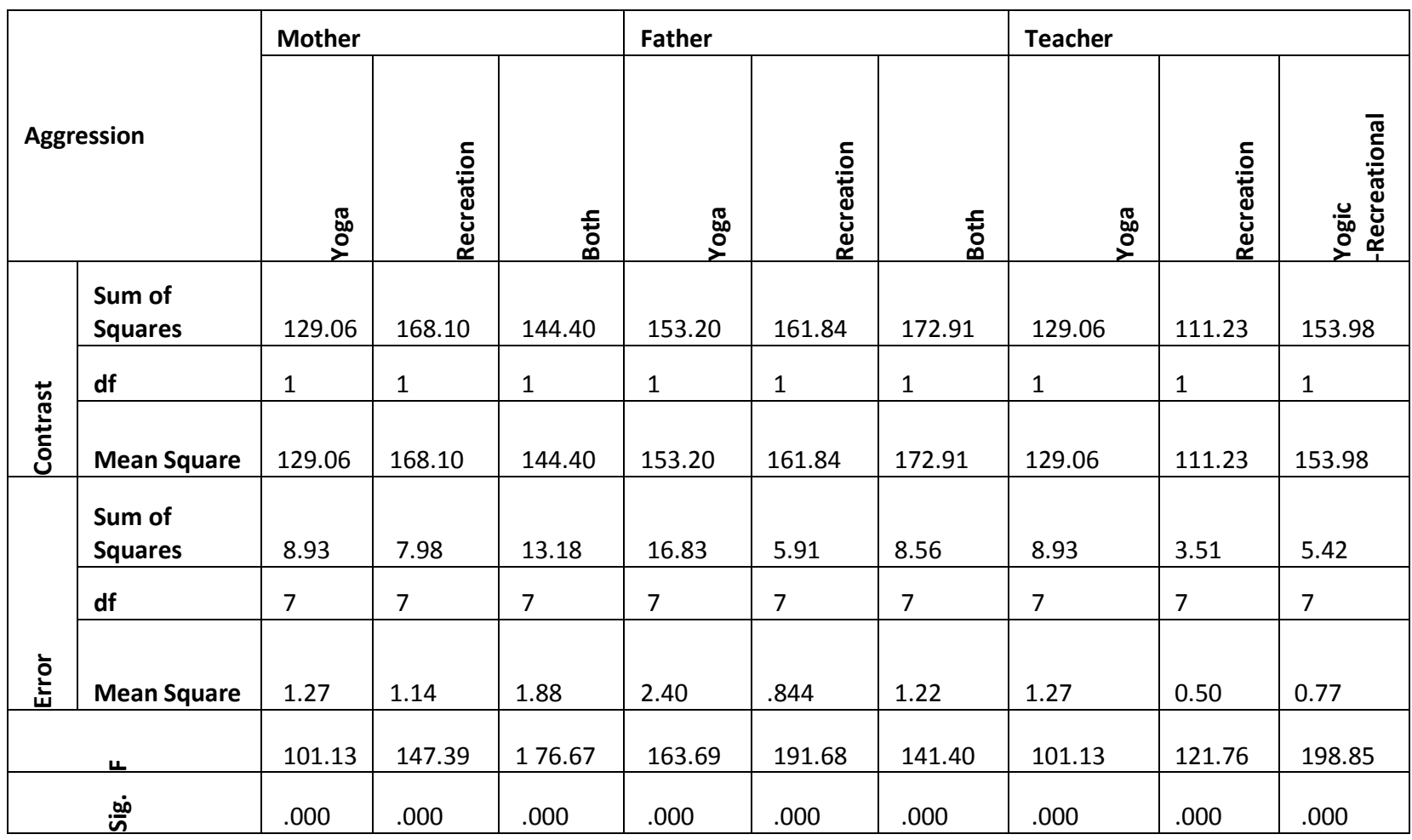

*Significant at 0.05 level $_{(1,7)} \mathrm{df}=\mathbf{5 . 5 9}$

Table 4 shows the $\mathrm{f}$ ratio of yoga, Recreation, Yogic-Recreational and Control groups in relation to self injurious behaviour of autistic children by mother, father and teacher.

In Yoga the Sig value was found .ooo, which is less than 0.05 and the calculated $f$-value for mother 101.13, father 163.69 and teacher 101.13 was found to be greater than tabulated value $=5.59$ at 1, $7 \mathrm{df}$, therefore it shows significant difference between the groups.

In Recreation the Sig value was found .ooo, which is less than 0.05 and the calculated $\mathrm{f}$ value for mother 147.39, father 191.68and teacher 121.76 was found to be greater than tabulated value $=5.59$ at $1,7 \mathrm{df}$, therefore it shows significant difference between the groups.

In Yoga-Recreation the Sig value was found .0oo, which is less than 0.05 and the calculated f-value for mother 176.67 , father 141.40, and teacher 198.85 was found to be greater than tabulated value $=5.59$ at $1,7 \mathrm{df}$, therefore it shows significant difference between the groups . 


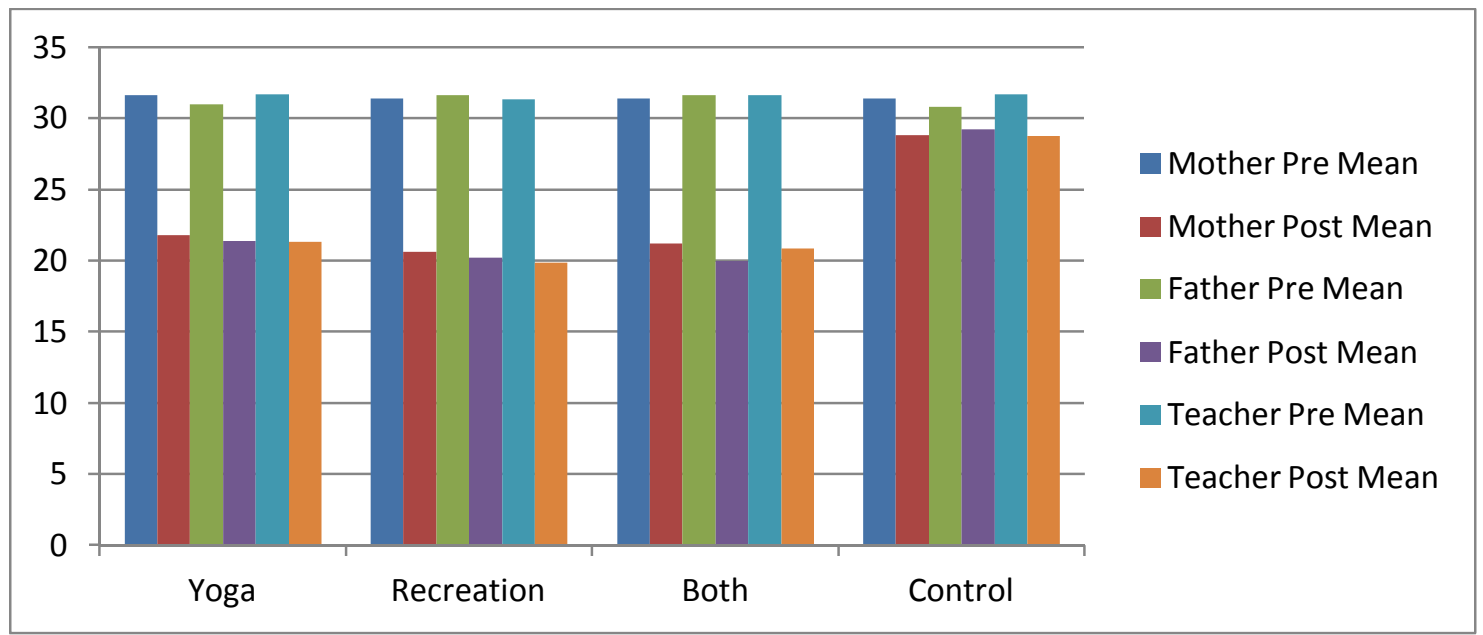

In the present study the investigators examined the effect of yogic and recreational activities training programme on self injurious and aggression behaviour of autistic children. The result of the present study shows significant difference in both experimental and control group on the variable self injurious and aggression behavior of autistic children. Self injurious and aggression behaviour occupies a large proportion of the behavioral repertoires of children with autism. These types of behavior act as obstacle for the future and the development of the children. Yogic and Recreational activities are associated with positive reinforcement in general. Role of yogic and recreational activities has been negligently examined with regards to autistic children treatment. Yogic and Recreational activities provide an opportunity to become physically active and provide some therapeutic benefit also. Result of the present study is also in line with Lang et.al (2010) who suggest that regular and specific type of physical activity program reduce self injurious and aggression behaviours in autistic children. Upcoming research with stronger substantiation planes, superior rigor, and longer-term result consideration is mandatory to determine precise exercise parameters. Despite limitations of systematic experiment the study suggests that yogic and recreational activities are beneficial, in reducing self injurious and aggression behaviours in children with autism.

\section{Conclusions}

The results of the study confirmed that yogic activities have a significant effect on self-injurious behavior of autistic children. Similar effect is also observed on the aggressive behavior of autistic children. Recreational activities also confirm the significant effect on self injury as well as on aggressive behavior of autistic children..Therefore it is concluded that yogic activities and recreational activities should be the part of adjustive therapy to the autistic children.

\section{References}

Feldman, H.M. (2005). Teaching yoga to school age children. International Journal of Yoga Therapy, 15, 8795.

Galantino, Galbavy, and Quinn (2008) Therapeutic effects of yoga for children: a systematic review of the literature.Pediatr Phys Ther. 2008 Spring;20(1):66-8o. doi: 10.1097/PEP.obo13e31815fizo8 
National Center for Complementary and Alternative Medicine. (2011). Yoga for health: An introduction. Retrieved July 25, 2011, from http://nccam.nih.gov/health/yoga/ introduction.htm

Russell Lang, Lynn Kern Koegel, Kristen Ashbaugh, April Regester, Whitney Ence, Whitney Smith (2010) Physical exercise and individuals with autism spectrum disorders: A systematic review Research in Autism Spectrum Disorders 4 (2010) 565-576

Uttam Aakriti (2012) Autism numbers rise in India. Retried from http://southasia.oneworld.net/news/indiahome-to-highest-number-of-autistic-patients-in-south-asia\#.VSkjqNyUc4F

Dr.Neelam Sharma is Assistant Professor, Lovely Professional University, Phagwara, Punjab.

Nidhi Sharma is Ph.D Scholar, Lovely Professional University, Phagwara, Punjab. 